\title{
Pengembangan Pembelajaran Sains Berbasis Inkuiri Terintegrasi Nature of Science (NoS) dan Pengaruhnya terhadap Penguasaan Konsep
}

\author{
Arika Masruroh, Ibrohim, Herawati Susilo \\ Pendidikan Biologi-Universitas Negeri Malang
}

\begin{tabular}{l}
\hline INFO ARTIKEL \\
\hline Riwayat Artikel: \\
Diterima: $13-02-2019$ \\
Disetujui: 18-04-2019 \\
\hline
\end{tabular}

Kata kunci:

science learning;

inquiry;

nature of science;

mastery of concepts;

pembelajaran sains;

inkuiri;

nature of science;

penguasaan konsep

\section{ABSTRAK}

Abstract: This development research is done to make a valid, practical, and effective, learning design and tools, and will be implemented for learning to examine the effect to the student concept mastery. Data collection uses validity sheets and practicality obtained from validators, the effectiveness and test hypotheses test obtained from the students. The research results are $85.55 \%$ valid, $90.00 \%$ practice, and $85 \%$ effective in increasing students' concepts mastery. Hypothesis test results have a value $(\mathrm{p}=0.001)$ $<(\alpha=0.05)$ which means a significant difference between the control class and the experimental class result. The implementation is better to done in the long term because Science Learning based on inquiry need a repeated training to get a maximum results.

\begin{abstract}
Abstrak: Penelitian pengembangan ini dilakukan untuk menghasilkan rancangan dan perangkat pembelajaran yang valid, praktis, dan efektif, serta diimplementasikan untuk mengkaji pengaruhnya terhadap penguasaan konsep siswa. Pengumpulan data menggunakan lembar penilaian kevalidan dan kepraktisan yang diperoleh dari validator, serta soal tes untuk uji keefektifan dan uji hipotesis diperoleh dari siswa. Hasil penelitian ialah $85,55 \%$ valid, $90,00 \%$ praktis, serta $85 \%$ efektif meningkatkan penguasaan konsep siswa. Hasil uji hipotesis memiliki nilai $(p=0,001)<(\alpha=0,05)$ yang artinya terdapat perbedaan signifikan antara hasil penguasaan kelas kontrol dengan kelas eksperimen. Implementasi sebaiknya dilakukan dalam jangka panjang karena pembelajaran inkuiri terintegrasi dengan Nature of Science (NoS) membutuhkan pelatihan yang berulang agar mencapai hasil maksimal.
\end{abstract}

\section{Alamat Korespondensi:}

Arika Masruroh

Pendidikan Biologi

Universitas Negeri Malang

Jalan Semarang 5 Malang

E-mail: caricakira@gmail.com

Salah satu pembelajaran yang ada pada kurikulum 2013 yaitu pembelajaran sains terintegrasi (KEMENDIKBUD, 2017). Tujuan utama pembelajaran sains adalah mempromosikan pemikiran ilmiah pada siswa termasuk menghasilkan pertanyaan penelitian, merancang sebuah penelitian, melakukan pengamatan, menjelaskan, mengembangkan teori, dan mempelajari penelitian orang lain (Chin \& Malhotra, 2002; Chin \& Chin, 2006), memahami sains secara benar dan bermakna, serta mampu memanfaatkan dalam kehidupan (Chin \& Chin, 2006; N. G. Lederman, Lederman, \& Antink, 2013). Pembelajaran sains lebih menekankan pada proses (Sheeba, 2013; Trefil, Hoffman, \& Hazen, 2000) sehingga siswa aktif selama pembelajaran untuk membangun pengetahuannya melalui serangkaian kegiatan agar pembelajaran menjadi bermakna bagi siswa (Sheeba, 2013), mengorganisasikan prinsip dari pengetahuan ilmiah dan aplikasinya dalam kehidupan sehari-hari (Trefil et al., 2000). Oleh karena itu perlu ditekankan pemahaman hakikat sains (Nature of Science) dalam pembelajaran (Lederman et al., 2013). Pemahaman tentang hakikat sains tersebut diapresiasi sebagai salah satu karakteristik yang diharapkan bagi seorang siswa, di mana orang tersebut secara umum mampu berliterasi sains, mengembangkan pemahaman konsep, prinsip, teori, dan proses sains (Norm G. Lederman, Abd-El-Khalick, Bell, \& Schwartz, 2002).

Pembelajaran yang sesuai dengan kurikulum 2013 dan memenuhi tuntutan pembelajaran sains, salah satu di antaranya inquiry learning (KEMENDIKBUD, 2016). Partisipasi dalam kegiatan inkuiri mendorong siswa untuk mengajukan pertanyaan, mengusulkan hipotesis, membuat prediksi, menggunakan alat, mengumpulkan dan menganalisis data, menghasilkan inferensi dari bukti empiris membuat argumen, mengomunikasikan temuan mereka dan menggunakan berbagai strategi penalaran yang melibatkan pemikiran kritis, kreatif, kausal, dan logis (Minstrell \& American Association for the Advancement of Science, 2000; Olson \& Horsley, 2000). Pembelajaran Inkuiri menuntut siswa untuk mencari pengetahuan dan mencari tahu tentang suatu fenomena (Andrini, 2016; Zubaidah, 2016), menggunakan konsep yang telah diadakan untuk memecahkan masalah yang dihadapi (Andrini, 2016), serta membantu memberdayakan keterampilan berpikir tingkat tinggi siswa (Barron \& Darling- 
Hammond, 2008; Thaiposri \& Wannapiroon, 2015). Setiap individu harus terlibat dalam pembelajaran berbasis inkuiri yang bermakna, memiliki nilai kebenaran dan relevansi, sehingga siswa akan memiliki pemahaman tentang hakikat sains yang sebenarnya yaitu sains sebagai proses, produk, dan sikap (Barron \& Darling-Hammond, 2008; Lederman et al., 2013).

Penerapan pembelajaran inkuiri diketahui mampu meningkatkan penguasaan konsep (Callahan, Quackenbush, \& Rowings, 1992; Kurniawati, Maskuri, \& Saputro, 2016; Kurniawati, Wartono, \& Diantoro, 2104) dan keterampilan berpikir (Musdar, Hasan, \& Halim, 2015). Pemberdayaan keterampilan berpikir juga mampu memberikan peningkatan pada penguasaan konsep siswa (Zubaidah, 2016). Tingkat keterampilan berpikir siswa telah menggambarkan kemampuan proses kognitif siswa yang sesungguhnya (Sribekti, Ibrohim, \& Hidayat, 2016). Penguasaan konsep adalah bentuk dari ekspresi keterampilan bahasa dan kemampuan kognitif yang sesuai dengan tingkatan kemampuan intelektual, aturan tata bahasa, prinsip ilmu pengetahuan, dan sejenisnya yang dimiliki siswa dalam melakukan tugas sekolah, bersikap dengan baik dan memiliki keterampilan yang relevan (Gagné, Briggs, \& Wager, 1992).

Praktiknya di sekolah pembelajaran sains masih lebih banyak melalui penjelasan verbal atau kegiatan belajar kelompok, diskusi atau praktikum yang bersifat pembuktian (Ibrohim, Munzil, \& Hariyanto, 2014; Sribekti, Ibrohim, \& Hidayat, 2016). Sehingga kurang mengarah pada kognitif level tinggi dan higher order thinking skills (Ibrohim et al., 2014). Hal tersebut cenderung menurunkan motivasi belajar siswa karena siswa hanya dituntut menghafalkan fakta bukan menemukan sesuatu sendiri (Chin \& Chin, 2006). Padahal motivasi belajar menunjukkan hubungan yang positif terhadap prestasi akademik siswa (Orhan Özen, 2017; Sharma \& Sharma, 2018). Kasus serupa terjadi di Indonesia pada SMP Lab UM sebagaimana yang dinyatakan oleh beberapa guru IPA dalam hasil wawancara, serta observasi pembelajaran secara langsung. Banyak siswa yang kesulitan membuat pertanyaan sains, menyampaikan hipotesis, merancang dan melaksanakan percobaan karena biasanya hanya kegiatan demonstrasi, menghubungkan antara data satu dengan yang lain, serta membuat kesimpulan berdasarkan data. Hal itu merupakan beberapa aspek keterampilan proses sains (Sheeba, 2013) yang artinya belum dimiliki oleh siswa SMP Lab UM hasil tes menunjukkan rata-rata nilai siswa hanya 44.91 .

Berdasarkan uraian latar belakang di atas maka sangat penting untuk dilakukan penelitian dengan judul Pengembangan Pembelajaran Berbasis Inkuiri Terintegrasi NoS dan Pengaruhnya terhadap Penguasaan Konsep Siswa. Tujuan penelitian ini adalah untuk menghasilkan pembelajaran yang valid, praktis, dan efektif serta untuk mengetahui pengaruh pembelajaran terhadap penguasaan konsep siswa. Model pengembangan yang digunakan mengikuti tahapan ADDIE, meliputi Analyze, Design, Develop, Implement, dan Evaluate. Rancangan instruksional pendekatan ADDIE dipilih karena bersifat generik dan merupakan paradigma pengembangan produk (Branch, 2009).

\section{METODE}

Jenis penelitian ini merupakan penelitian pengembangan yang menggunakan model ADDIE (Analyze, Design, Develope. Implement, Evaluate). Produk pengembangan berupa perangkat yang akan divalidasi oleh ahli materi, perangkat pembelajaran, dan praktisi lapangan. Penelitian ini dilaksanakan pada bulan November 2018 sampai April 2019 di SMP Laboratorium Universitas Negeri Malang. Hasil pengembangan akan diimplementasikan untuk mengetahui perbandingan antara pengaruh antara kelas yang diberi pembelajaran inkuiri terintegrasi NoS (Eksperimen) dengan kelas yang diberi pembelajaran dengan modul dan beberapa praktikum verifikatif (Kontrol). Kelas eksperimen adalah kelas 7D yang berjumlah 32 siswa dan kelas kontrol adalah kelas 7C yang berjumlah 32 siswa. Sebelum diberikan perlakuan berupa pembelajaran kelas diberikan pretes, kemudian setelah diberi pembelajaran yang berbeda dilakukan postes. Desain quasi eksperimen menggunakan non-randomized pretest postest control group design, seperti pada tabel 1. Penentuan sampel ini menggunakan uji kesetaraan, dari empat kelas diperoleh dua kelas tersebut. Pengumpulan data menggunakan lembar observasi dan tes uraian. Analisis data menggunakan deskriptif kuantitatif.

Tabel 1. Desain Penelian Quasi Eksperimen

\begin{tabular}{lccc}
\hline Kelas & Tes awal & Perlakuan & Tes akhir \\
\hline Kelas Eksperimen & $T 1$ & $\mathrm{X}$ & $T 2$ \\
Kelas Kontrol & $T 3$ & - & $T 4$ \\
\hline
\end{tabular}

Keterangan:

T1 : pemberian tes awal pada kelas eksperimen

T3 : pemberian tes awal pada kelas kontrol

$\mathrm{X} \quad$ : pembelajaran berbasis inkuiri terintegrasi Nature of Science (NoS)

- $\quad$ : pembelajaran berbasis modul dan praktikum verifikatif

T2 : pemberian tes akhir pada kelas eksperimen

T4 : pemberian tes akhir pada kelas kontrol 


\section{HASIL}

Pembelajaran sains berbasis inkuiri dan NoS, merupakan pembelajaran sains yang menggunakan model inkuiri dalam pembelajaran dan mengeksplisitkan NoS di dalam pembelajaran. Pengembangan pembelajaran tersebut menghasilkan sebuah perangkat yang akan digunakan dalam pembelajaran. Perangkat tersebut, meliputi Silabus, Rancangan Rencana Pembelajaran, Lembar Kerja Siswa, dan Handout pada materi interaksi makhluk hidup, pencemaran lingkungan, dan pemanasan global. Sebelum dilakukan uji coba dan implementasi dilakukan terlebih dahulu validasi. Uji validasi dilakukan oleh tiga orang ahli, yakni ahli materi, ahli perangkat pembelajaran, dan praktisi lapangan. Hasil validasi ahli tentang perangkat pembelajaran secara ringkas pada tabel 2 .

Tabel 2. Rangkuman Rerata Nilai Hasil Validasi Perangkat Pembelajaran

\begin{tabular}{lccc}
\hline Komponen Perangkat & Ahli Materi (\%) & Ahli Perangkat (\%) & Praktisi Lapangan (\%) \\
\hline Silabus & 80,95 & 88,75 & 97,22 \\
RPP & 83,75 & 89,09 & 96,05 \\
LKS & 82,69 & 80,00 & 100,0 \\
Handout & 88,75 & - & 92,50 \\
Instrumen Penilaian & 94,04 & 78,46 & 98,48 \\
\hline
\end{tabular}

Hasil kepraktisan diperoleh dari pengamatan pembelajaran yang dilakukan oleh observer dan respon siswa. Rata-rata pembelajaran sebesar 93\% artinya pembelajaran terlaksana sesuai rancangan yang sudah dikembangkan. Hasil persentase ratarata yang diperoleh dari hasil pengisian angket respons terhadap LKS dan handout memperoleh rata-rata berturut sebesar 86,8\% dan $85,4 \%$, kedua hasil tersebut termasuk kriteria baik. Hasil uji keefektifan mendapatkan nilai rata-rata 80,00 dengan 13 orang siswa yang tuntas, sedangkan dua lainnya masih belum tuntas.

\section{Hasil Implementasi}

Hasil uji normalitas menunjukkan nilai $\mathrm{p}(0,200)>\alpha(0,05)$, dengan demikian data dapat dikatakan terdistribusi secara normal. Hasil uji homogenitas menunjukkan nilai $\mathrm{p}(0,272)>\alpha(0,05)$. Nilai tersebut menunjukkan bahwa data postes homogen atau memiliki varian yang sama berasal dari populasi yang sama. Setelah uji prasyarat terpenuhi maka dilakukan uji hipotesis menggunakan ANAKOVA. Rangkuman hasil uji anakova untuk mengetahui perbedaan pencapaian penguasaan konsep siswa pada kedua kelas yang digunakan pada penelitian ini ditunjukkan pada tabel 3.

Tabel 3. Rangkuman Hasil Uji Anakova Pencapaian Penguasaan Konsep Siswa

\begin{tabular}{cccccc}
\hline \multicolumn{7}{c}{ Dependent Variable: } & Penguasaan Konsep & \\
\hline Source & $\begin{array}{c}\text { Type III Sum } \\
\text { of Squares }\end{array}$ & df & Mean Square & F & Sig. \\
\hline Corrected Model & $17133,652^{\text {a }}$ & 2 & 8566,826 & 109,576 &, 000 \\
Intercept & 4387,697 & 1 & 4387,697 & 56,122 &, 000 \\
Pretes & 4692,052 & 1 & 4692,052 & 60,015 &, 000 \\
Kelas & 14813,020 & 1 & 14813,020 & 189,470 &, 000 \\
Error & 4456,348 & 57 & 78,182 & & \\
Total & 223430,000 & 60 & & \\
Corrected Total & 21590,000 & 59 & \\
\hline \multicolumn{7}{c}{}
\end{tabular}

Berdasarkan hasil uji anakova tersebut, diketahui bahwa nilai signifikansi perbedaan rerata skor antara kontrol dan eksperimen $(p=0,001)<(\alpha=0,05)$. Nilai ini berarti terdapat perbedaan signifikan penguasaan konsep siswa kelas kontrol yang diajarkan dengan menggunakan modul dan praktikum verifikatif dengan kelas eksperimen yang menggunakan pembelajaran inkuiri terintegrasi NoS. Artinya, pembelajaran inkuiri terintegrasi NoS berpengaruh secara signifikan terhadap pencapaian tingkat penguasaan konsep siswa.

\section{PEMBAHASAN \\ Hasil Uji Validasi Perangkat Pembelajaran}

Validasi bertujuan sebagai penilaian evaluatif terhadap suatu produk berdasarkan pada bukti empiris dan alasan-alasan teoritis yang mendukung dan mengetahui tingkat validitas dari perangkat pembelajaran yang telah dikembangkan (Messick, 1987). Validasi dilakukan oleh tiga orang validator, yaitu ahli materi, ahli perangkat pembelajaran, dan praktisi lapangan. Persentase rata-rata skor sebesar $89,33 \%$ dengan kriteria valid dan dapat digunakan dalam pembelajaran, namun dengan revisi (Arikunto, 2010). Hasil yang diberikan validator sudah valid meskipun tidak mencapai 100\%. Oleh karena itu, ada beberapa aspek yang perlu direvisi dan diteliti kembali sesuai komentar atau saran dari validator terhadap perangkat pembelajaran. 
Revisi dilakukan pada bagian silabus, RPP, LKS, dan handout, misalnya kesesuaian indikator dengan kegiatan pembelajaran serta kekonsistenan antar KD dan indikator, sesuai yang telah dijelaskan dalam standar proses pendidikan (KEMENDIKBUD, 2016). Penilaian sebaiknya diperjelas apa yang akan dinilai misalnya keterampilan berpikir kritis dan kreatif dan disesuaikan dengan tujuan pembelajaran. Tujuan pembelajaran sebaiknya menggunakan rumus ABCD (Audience, Behaviour, Condition, Degree), misalnya siswa mampu menganalisis komponen penyusun ekosistem melalui kegiatan pengamatan ekosistem buatan yang dilakukan setiap hari. Tujuan disusun sedemikian rupa agar mampu mendefinisikan secara instruksional keterampilan yang diharapkan dalam suatu proses pembelajaran (Gagné et al., 1992). LKS diberikan redaksi yang jelas sesuai dengan tujuan penelitian dan tujuan dalam RPP dan setiap kegiatan pembelajaran harus sama antara LKS satu dengan yang lain. LKS sebaiknya menggunakan kata kerja operasional sehingga siswa lebih mudah memahami dan mengidentifikasi permasalahan, serta tidak menimbulkan ambiguinitas (Fitriyanti, Hasmidyani, Barlian, Firmansyah, \& Waikelak, 2014). Terakhir yaitu memperbaiki font handout agar lebih sesuai proporsional dan memperjelas gambar yang ada di dalam handout. Kriteria valid penting bagi sebuah perangkat pembelajaran. Selain itu, pembelajaran yang disajikan haruslah memotivasi siswa, disajikan dengan bahasa baik dan menarik serta akurat (UNESCO, 2013).

\section{Hasil Uji Kepraktisan Perangkat Pembelajaran}

Uji kepraktisan perangkat pembelajaran dilakukan dengan tujuan untuk mengetahui produk perangkat pembelajaran yang dikembangkan bisa diterapkan atau tidak di kelas. Hasil uji kepraktisan memperoleh nilai rerata sebesar 93\% dan memiliki kategori praktis (Arikunto, 2010). Nilai tersebut menunjukkan bahwa perangkat pembelajaran praktis dan mudah digunakan oleh semua orang karena nilai yang didapatkan dalam kategori tinggi (Akker \& Interuniversitair Centrum voor Onderwijskundig Onderzoek, 1999). Hasil ini menunjukkan bahwa perangkat pembelajaran yang dikembangkan secara konstruk dan materi sangat praktis untuk digunakan dalam penerapan pembelajaran di sekolah. Meskipun hasil kepraktisan menunjukkan kriteria yang baik, masih ada beberapa kekurangan pada saat proses pembelajaran seperti pengelolaan waktu yang tidak tepat waktu. Hal itu terjadi karena siswa masuk kelas tidak tepat akibat mengikuti kegiatan lain sehingga guru perlu mengulang penjelasan yang bisa memperpanjang waktu mengajar. Selain itu, ada video yang kurang kontekstual atau dekat dengan kehidupan siswa seperti video perkiraan cuaca, seharusnya mengambil di sekitar Jawa Timur agar siswa dapat mengetahui cuaca di Jawa Timur. Peneliti kesulitan mendapatkan video perkiraan cuaca di sekitar Jawa Timur sehingga menggunakan video Jabodetabek.

\section{Hasil Uji Keefektifan Perangkat Pembelajaran}

Uji keefektifan dilakukan untuk melihat bagaimana respon siswa selama pembelajaran. Respon yang dimaksud adalah berupa peningkatan nilai siswa (Akker \& Interuniversitair Centrum voor Onderwijskundig Onderzoek, 1999), dalam penelitian ini berarti peningkatan penguasaan konsep siswa. Hasil uji keefektifan mendapatkan nilai rata-rata 80,00 dengan 13 orang siswa yang tuntas, sedangkan dua lainnya masih belum tuntas. Nilai penguasaan konsep siswa mengalami peningkatan daripada nilai sebelum pembelajaran inkuiri terintegrasi NoS. Nilai penguasaan konsep siswa mengalami peningkatan setelah dibelajarkan menggunakan inkuiri terintegrasi NoS. Pembelajaran dikatakan efektif apabila 85\% dari 100\% siswa mampu mencapai minimal 75 dari skor maksimal 100 (Hobri, 2009). Artinya, siswa memberikan respon positif terhadap pembelajaran (Akker \& Interuniversitair Centrum voor Onderwijskundig Onderzoek, 1999). Hasil tersebut menunjukkan bahwa pembelajaran inkuiri terintegrasi NoS bisa mengembangkan atau meningkatkan penguasaan konsep siswa (Andrini, 2016; Yulianci, Gunawan, \& Doyan, 2017).

Berdasarkan hasil uji validasi, kepraktisan, dan kevalidan, maka diperoleh hasil bahwa perangkat pembelajaran yang dikembangkan sudah valid, praktis, dan efektif. Tahap selanjutnya, implementasi. Implementasi dilakukan untuk menguji apakah ada pengaruh pembelajaran inkuiri terintegrasi NoS terhadap penguasaan konsep siswa.

\section{Pengaruh Pembelajaran Inkuiri Terintegrasi NoS terhadap Penguasaan Konsep}

Berdasarkan hasil uji anakova diketahui bahwa nilai signifikansi perbedaan rerata skor antara kontrol dan eksperimen $(p=0,001)<(\alpha=0,05)$. Nilai ini berarti terdapat perbedaan signifikan penguasaan konsep siswa kelas kontrol yang diajarkan dengan menggunakan modul dan praktikum verifikatif dengan kelas eksperimen yang menggunakan pembelajaran inkuiri terintegrasi NoS. Peningkatan nilai penguasaan konsep siswa pada kelas eksperimen dikarenakan siswa terbiasa berinkuiri dan terlatih memahami tentang NoS. Pertama mengeksplorasi fenomena, tahap ini bertujuan agar siswa mampu membaca fenomena dan menemukan masalah. Siswa memahami konsep pertama harus didasari dengan pencarian (Kuhlthau, Maniotes, \& Caspari, 2007). Setelah menemukan masalah siswa merumuskan permasalahan terkait fenomena disajikan. Penguasaan konsep erat kaitannya dengan identifikasi permasalahan dan pemecahan masalah (Dahan, 2011). Selanjutnya. tahap inti yaitu merancang dan melakukan percobaan yang bertujuan untuk mengumpulkan data, tahap ini mampu meningkatkan penguasaan konsep siswa karena melalui inkuiri siswa dituntut untuk mencari informasi, menyelidiki, dan membangun ide untuk menguatkan konsep dasar yang mereka miliki (Barron \& Darling-Hammond, 2008; Kuhlthau et al., 2007; Olson \& Horsley, 2000). 
Tahap terakhir adalah menganalisis data dan menyimpulkan, setelah mendapatkan suatu data siswa harus mengasosiasi dan menghubungkan data sampai terbentuk kesimpulan yang utuh. Kesimpulan tersebut adalah bentuk dari konsep yang siswa temukan (Kuhlthau et al., 2007).

Pembelajaran inkuiri baik diterapkan dalam pembelajaran dalam membangun konsep sains (Barron \& DarlingHammond, 2008). Melalui inkuiri siswa diberikan kesempatan mengembangkan dan menemukan konsep mereka sendiri (Kuhlthau et al., 2007). Pembelajaran inkuiri mampu melatihkan siswa menemukan sendiri konsep dan menggunakan berbagai strategi penalaran yang melibatkan pemikiran kritis, kreatif, kausal, dan logis (Minstrell \& American Association for the Advancement of Science, 2000; Olson \& Horsley, 2000). Pembelajaran Inkuiri menuntut siswa untuk mencari pengetahuan dan mencari tahu tentang suatu fenomena (Andrini, 2016; Zubaidah, 2016), menggunakan konsep yang telah diadakan untuk memecahkan masalah yang dihadapi (Andrini, 2016), serta membantu memberdayakan keterampilan berpikir tingkat tinggi siswa (Barron \& Darling-Hammond, 2008; Thaiposri \& Wannapiroon, 2015). NoS yang sering dilatihkan juga mampu berliterasi sains, mengembangkan pemahaman konsep, prinsip, teori, dan proses sains (Lederman et al., 2013; Lederman et al., 2002).

Berdasarkan jabaran tersebut artinya pembelajaran inkuiri terintegrasi NoS berpengaruh secara signifikan terhadap pencapain tingkat penguasaan konsep siswa atau mampu meningkatkan penguasaan konsep siswa (Cabe Trundle, Atwood, Christopher, \& Sackes, 2010; Callahan et al., 1992; Kurniawati et al., 2016; Kurniawati et al., 2104; Kusdiastuti, Harjono, Sahidu, \& Gunawan, 2017). Secara keseluruhan, nilai penguasaan konsep siswa memiliki kriteria tinggi namun nilai yang didapatkan siswa tidak seragam. Hal ini dipengaruhi oleh banyak faktor baik dari dalam individu maupun dari situasi yang memengaruhi kognitif siswa (Lai, 2011).

\section{SIMPULAN}

Berdasarkan hasil kajian hasil dan pembahasan maka dapat disimpulkan bahwa hasil dari pengembangan pembelajaran berbasis inkuiri dan NoS ini adalah perangkat pembelajaran yang dinyatakan valid, praktis, dan efektif. Selanjutnya pembelajaran ini dikatakan berpengaruh terhadap pencapaian penguasaan konsep siswa. Hasil tersebut diperoleh berdasarkan perbedaan signifikan antara hasil penguasaan konsep kelas kontrol dan eksperimen.

Apabila menginginkan perangkat yang sangat valid sebaiknya diperhatikan komponen penting dari isi masing-masing perangkat, misalnya menggunakan panduan PERMENDIKBUD tentang standar proses. Jika menginginkan hasil yang lebih signifikan lebih baik implementasi dalam jangka panjang karena inkuiri dan NoS membutuhkan pelatihan yang berulang agar mencapai hasil maksimal. Penelitian ini dapat dijadikan rujukan untuk mengembangkan produk lain dengan materi berbeda dan melatihkan variabel yang berbeda, misalnya kemampuan berpikir atau keterampilan proses sains siswa.

\section{DAFTAR RUJUKAN}

Akker, J. J. H. van den., \& Interuniversitair Centrum voor Onderwijskundig Onderzoek (Eds.). (1999). Design Approaches and Tools in Education and Training. Dordrecht; Boston: Kluwer Academic Publishers.

Andrini, V. S. (2016). The Effectiveness of Inquiry Learning Method to Enhance Students' Learning Outcome: A Theoritical and Empirical Review. Journal of Education and Practice, 7(3), 38-42.

Arikunto, S. (2010). Prosedur Penelitian: Suatu Pendekatan Praktik. Jakarta: Rineka Cipta.

Barron, B., \& Darling-Hammond, L. (2008). Teaching for Meaningful Learning: A Review of Research on Inquiry-Based and Cooperative Learning. news@edutopia.org; Web site: http://www.edutopia.org: George Lucas Educational Foundation.

Branch, R. M. (2009). Instructional Design: The ADDIE Approach. https://doi.org/10.1007/978-0-387-09506-6

Cabe Trundle, K., Atwood, R. K., Christopher, J. E., \& Sackes, M. (2010). The Effect of Guided Inquiry-Based Instruction on Middle School Students' Understanding of Lunar Concepts. Research in Science Education, 40(3), 451-478. https://doi.org/10.1007/s11165-009-9129-x

Callahan, M. T., Quackenbush, D. G., \& Rowings, J. E. (1992). Construction project scheduling. New York: McGraw-Hill.

Chin, C. A., \& Malhotra, B. A. (2002). Epistemologically Authentic Inquiry in Schools: A Theoretical framework for Evaluating Inquiry Tasks. Science Education, 86(2), 175-218.

Chin, C., \& Chin, L. G. (2006). Problem-Based Learning: Using Ill-Structured Problems in Biology Project Work. Science Education, 99(1), 44-67.

Dahan, R. W. (2011). Teori Belajar \& Pembelajaran. Jakarta: Erlangga.

Fitriyanti., Hasmidyani, D., Barlian, I., Firmansyah, \& Waikelak, K. S. (2014). Pelatihan Penyusunan LKS Berbasis Kurikulum 2013 pada Mata Pelajaran Ekonomi dan Akuntansi di SMA/SMK Swasta Se-Kecamatan Kemuning Palembang. Jurnal Provit, 1(2), 133-140.

Gagné, R. M., Briggs, L. J., \& Wager, W. W. (1992). Principles of instructional design (4th ed). Fort Worth: Harcourt Brace Jovanovich College Publishers. 
Ibrohim, Munzil, \& Hariyanto. (2014). Penerapan Pembelajaran IPA Berbasis Inkuiri Berbahan Ajar Potensi Lokal untuk Mengembangkan Keterampila dan Sikap Ilmiah Siswa SMP di Kabupaten Pasuruan melalui Kegiatan Lesoon Study. Prosiding Seminar Nasional Pendidikan Sains; Inovasi Pendidikan Sains Dalam Menyongsong Pelaksanaan Kurikulum 2013.

KEMENDIKBUD. (2016). Salinan Lampiran Peraturan Menteri Pendidikan dan Kebudayaan Nomor 22 Tahun 2016 Tentang Standar Proses Pendidikan Dasar dan Menengah. Sidan Kementrian. Presented at the Jakarta. Jakarta: Direktur Jenderal Peraturan Perundang-Undangan Kementerian Hukum dan Hak Asasi Manusia Republik Indonesia.

KEMENDIKBUD. (2017). Peraturan Menteri Pendidikan dan Kebudayaan. KEMENDIKBUD.

Kuhlthau, C. C., Maniotes, L. K., \& Caspari, A. K. (2007). Guided Inquiry: learning in the 21 st century. Westport, Conn: Libraries Unlimited.

Kurniawati, D., Maskuri, M., \& Saputro, S. (2016). Penerapan Model Pembelajaran Inkuiri Terbimbing Dilengkapi LKS untuk Meningkatkan Keterampilan Proses Sains dan Prestasi Belajar pada Materi Pokok Hukum Dasar Kimia Siswa Kelas X MIA 4 SMA N 1 Karanganyar Tahun Pelajaran 2014/2015. Jurnal Pendidikan Kimia, 5(1), 88-95.

Kurniawati, I. D., Wartono, \& Diantoro, M. (2104). Pengaruh Pembelajaran Inkuiri Terbimbing Integrasi Peer Instruction terhadap Penguasaan Konsep dan Kemampuan Berpikir Kritis Siswa. Jurnal Pendidikan Fisika Indonesia, 10, 36-46.

Kusdiastuti, M., Harjono, A., Sahidu, H., \& Gunawan, G. (2017). Pengaruh Model Pembelajaran Inkuiri Berbantuan Laboratorium Virtual terhadap Penguasaan Konsep Fisika Peserta Didik. Jurnal Pendidikan Fisika dan Teknologi, 2(3), 116. https://doi.org/10.29303/jpft.v2i3.298

Lai, E. R. (2011). Metacognition: A Literature Review. Pearson Research Report. Pearson Education.

Lederman, N. G., Lederman, J. S., \& Antink, A. (2013). Nature of Science and Scientific Inquiry as Contexts for the Learning of Science and Achievement of Scientific Literacy. International Journal of Education in Mathematics, Science and Technology, 3(1), 138-147.

Lederman, Norm G., Abd-El-Khalick, F., Bell, R. L., \& Schwartz, R. S. (2002). Views of Nature of Science Questionnaire: Toward valid and Meaningful Assessment of Learners' Conceptions of Nature of Science. Journal of Research in Science Teaching, 39(6), 497-521. https://doi.org/10.1002/tea.10034

Messick, S. (1987). Validity. ETS Research Report Series, 1987(2), i-208. https://doi.org/10.1002/j.2330-8516.1987.tb00244.x

Minstrell, J., \& American Association for the Advancement of Science (Eds.). (2000). Inquiring into inquiry learning and teaching in science. Washington: AAAS.

Musdar., Hasan, M., \& Halim, A. (2015). Efektivitas Penggunaan Model Inkuiri Terbimbing dengan Kegiatan Laboratorium Virtual Materi Fluida Statis untuk Meningkatkan Pemahaman Konsep dan Keterampilan Berpikir Kritis Siswa. Jurnal Pendidikan Sains Indonesia, 3(1), 114-124.

Olson, S., \& Horsley, S. L. (2000). Inquiry and the National Science Education Standards: A Guide for Teaching and Learning. https://doi.org/10.17226/9596

Orhan Özen, S. (2017). The Effect of Motivation on Student Achievement. In E. Karadag (Ed.), The Factors Effecting Student Achievement (pp. 35-56). https://doi.org/10.1007/978-3-319-56083-0_3

Sharma, D., \& Sharma, S. (2018). Relationship between motivation and academic achievement. International Journal of Advances in Scientific Research, 4(1), 01. https://doi.org/10.7439/ijasr.v4i1.4584

Sheeba, M. N. (2013). An Anatomy of Science Process Skills In The Light Of The Challenges to Realize Science Instruction Leading To Global Excellence in Education. Educationia Confab, 2(4), 108-123.

Sribekti, A., Ibrohim., \& Hidayat, A. (2016). Peningkatan Keterampilan Proses Sains dan Hasil Belajar Kognitif Siswa Kelas VII SMP Negeri 1 Selorejo menggunakan Perangkat Pembelajaran Ekosistem Berbasis Inkuiri Terbimbing dengan Sumber Belajar Waduk Lahor. Jurnal Pendidikan: Teori, Penelitian, dan Pengembangan, 1(8), 1575-1580.

Thaiposri, P., \& Wannapiroon, P. (2015). Enhancing Students' Critical Thinking Skills through Teaching and Learning by Inquiry-based Learning Activities Using Social Network and Cloud Computing. Procedia - Social and Behavioral Sciences, 174, 2137-2144. https://doi.org/10.1016/j.sbspro.2015.02.013

Trefil, J., Hoffman, Megan. M., \& Hazen, Robert. M. (2000). The Sciences: An Integrated Approach, 2nd Edition. Journal of Chemical Education, 77(1), 32. https://doi.org/10.1021/ed077p32

UNESCO. (2013). International Bureau of Education: Training Tools for Curriculum Development. A Resource Pack. Geneva Switzerland.

Yulianci, S., Gunawan, G., \& Doyan, A. (2017). Model Inkuiri Terbimbing Berbantuan Multimedia Interaktif untuk Meningkatkan Penguasaan Konsep Fisika Peserta Didik. Jurnal Pendidikan Fisika dan Teknologi, 3(2), 146. https://doi.org/10.29303/jpft.v3i2.365

Zubaidah, S. (2016). Keterampilan Abad Ke-21: Keterampilan yang Diajarkan melalui Pembelajaran. Isu-Isu Strategis Pembelajaran MIPA Abad 21. Presented at the Seminar Nasional Pendidikan, Kalimantan Barat. 